\title{
Ecological-economic assessment of ecological sanitation development in the cities of Chinese Loess Plateau
}

\author{
Chuanbin Zhou, Jingru Liu*, Rusong Wang, Wenrui Yang, Jiasheng Jin

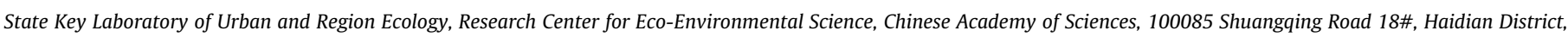 \\ Beijing, China
}

\section{A R T I C L E I N F O}

\section{Article history:}

Received 7 January 2008

Received in revised form 9 September 2009 Accepted 19 October 2009

\section{Keywords:}

Ecological sanitation

Loess Plateau

Ecological-economic assessment

Urban

\begin{abstract}
A B S T R A C T
Many cities in Chinese Loess Plateau have inadequate sanitation. Ecological sanitation (ecosan) is a systemic approach to solve environmental and sanitary problems. Thus, suitable ecosan technologies and systems were analyzed, and three alternative developing models of sanitation were compared, namely, centralized traditional (CT) model, centralized ecosan (CE) model, and centralized and decentralized mixed ecosan (ME) model. Their ecological-economic assessment was made in the theoretical framework of social-economic-natural complex ecological system. Main results were (1) CE and ME reduced the emission of greenhouse gases, and the maximum reduction was $96.8 \%$ of CT. (2) ME reduced the water pollutants at a comparatively lower capital and running cost, and $\mathrm{BOD}_{5}$ emission could be reduced to $85-88 \%$ of CT. (3) CE and ME reclaimed more nutrients than CT. Attributing to reclaiming nutrients, CE and ME could produce 461.4 and $809.9 \mathrm{Gg}$ foods, respectively, and CT was $32.1 \mathrm{Gg}$. (4) The sequence of health risk caused by sanitation was $\mathrm{CT}>\mathrm{CE}>\mathrm{ME}$. (5) Urban ecosan system could bring forward a maximum net benefit of 0.267 billion RMB. In addition, the bottlenecks of developing ecosan in China were also discussed in this paper.
\end{abstract}

(C) 2009 Elsevier B.V. All rights reserved.

\section{Introduction}

Organic wastes discharged from urban communities (including food waste, faeces, urine, and grey water) have been given more attention due to their global and regional ecological impacts. For example, uncontrolled waste landfill disposal sites, sewage ponds, and sludge digest facilities account for $10 \%$ of the greenhouse gases (GHGs) emission in China (Office of National Coordination Committee on Climate Change, 2001). Organic wastes result in health problems, such as diarrhea, hepatitis, and cancer, by means of contaminating water and food (Xu et al., 2003; Winblad and Hebert, 2006). Urbanization in China is occurring rapidly and many newly built urban areas are facing problems of inadequate sanitation services. Only $72 \%$ Chinese cities could access to freshwater that reached the national standard (year 2006).

Ecological sanitation (ecosan) is a systemic approach to solve environmental and sanitary problems. The basic principle of ecosan is "respect the ecological integrity in the sanitary systems" (Black, 2001; Langergraber and Muellegger, 2005). Ecosan focuses on the harmless treatment of the waste and security of fresh water. Water, nutrient, and biogas are recycled and the ecological loop of materials and energy is closed (Black, 2001; Winblad and Hebert,

\footnotetext{
* Corresponding author. Fax: +861062849110

E-mail address: liujingru@rcees.ac.cn (J. Liu).
}

2006). But some disadvantages of urban ecosan systems, such as psychosocial acceptance and public management difficulties, also have been found (Dellstrom Rosenquist, 2005).

Urban ecosan systems are varied in the different regions of China, which may be attributed to the geographic, economic, and cultural differences. In China, the northwest has lower temperatures and is semiarid; the southwest is temperate and moist; the northeast has very low temperatures in winter and remains frozen; the middle and the coastal areas are temperate and rainy. At the same time, the social and economic differences are evident. The West is less developed than the East and the coastal areas. Therefore, the regional differences should be respected when developing ecosan systems in China (Wang and Zhou, 2007).

Objective and comprehensive ecological-economic assessment was needed to develop urban ecosan systems in China since it is useful in the promotion of support for finances, policies, and legislations (Wang and Zhou, 2007). There are several methods for assessing solid waste and wastewater management systems. Life cycle analysis (LCA) was a useful method to identify and calculate the systemic material flow of pollutants and nutrients (Lundie and Peters, 2005; Shmelev and Powell, 2006), while the organic waste research (ORWARE) model could precisely perform a substanceflow simulation and find a relationship between substance-flow and economic benefits (Sonesson et al., 2000). There were two studies that integrated solid waste and wastewater system in the city level, and the factors of pollutions, recyclable nutrients, 
consumption of energy, cost, and benefits were assessed (Sonesson et al., 2000; Magid et al., 2006). However, the ecosan system is a complex eco-system that integrated social, economic, and natural factors (Wang, 2001; Dellstrom Rosenquist, 2005; Magid et al., 2006; Nawab et al., 2006), wherein a comprehensive framework of different subsystems should be established for understanding and unravelling complexity (Tainter, 2006; Saravanan, 2008).

The Loess Plateau is a typical semiarid region on the upper reaches of the Yellow River in the west of China (see Fig. 1). Fiftyone cities of eighteen million people in this region (belonging to Ningxia, Shaanxi, Gansu, Shanxi, and Inner Mongolia Province) are facing problems of inadequate sanitation and lack fresh water. With the consideration of regional differences in sanitation, we analyzed suitable ecosan technologies and integrated eight ecosan systems, and then established three ecosan developing models for the study area. In addition, the developing models of ecosan were assessed based on the theoretical framework of social-economicnatural complex ecological system (Ma and Wang, 1984).

\section{Methods}

\subsection{Matrix of unit technologies}

Ecosan is a system that integrated different unit technologies aiming for sustainable use of organic solid waste, faeces, urine, and grey water. Furthermore, there are two organization ways of technologies, namely, centralized and decentralized technologies (Magid et al., 2006). Thus, matrix of sanitary technologies is as follows:
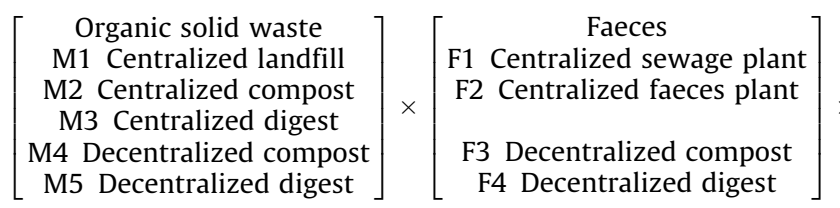

Feasibility and applicability of unit technologies should be analyzed before integrating ecosan systems. First, both centralized and decentralized systems are available for urban sanitation. Centralized technologies were generally applied in urban areas, such as landfills, digesting sites, and sewage plants, especially in the already built urban areas. The decentralized technologies were also important for sustainable sanitation (Otterpohl et al., 1997; Wilderer and Schreff, 2000). Many newly built urban communities of Beijing, Shanghai, Ningbo, Jinhua, among others had equipped the decentralized facilities for treating sewage and municipal solid waste.

Second, co-treatment of waste is feasible. As an example, organic waste with high moisture content could be co-digested with sludge and faeces, and has a high recycling potential for energy and biomass (Mata-Alvarez et al., 2000). There is a trend toward using larger and sophisticated co-digesting systems with better process controls that could generate electricity in China (Lusk, September 1998). Other research also shows that decentralized co-digestion of faeces and organic solid waste is also available (Chen et al., 2005). Urban community equipped with alternative urine diversion dry toilet (UDDT) and waste co-compost facilities were built up and demonstrated as much as possible in Ordos, Inner Mongolia, which is located in our study area (Sun et al., 2006).

Last, ecosan systems with low-cost and high potential of conserving water and reclaiming nutrients are a priority to the poor, dry, and barren Loess Plateau region. Comparatively expensive technologies, such as incineration of municipal solid waste, were not put into the matrix with the consideration of economic feasibility.
We integrated eight ecosan systems according to the analysis of technical feasibility and applicability (see Table 1 ).

\subsection{Material flow analysis}

Material flow of GHGs, water pollutants, nutrients, and capital and running cost were considered. An input and output inventory of the materials, energy, and money was developed using LCA and cost benefit analysis (CBA): (1) input: food waste, faeces, urine, grey water, electricity, gasoline, and capital and running cost; (2) output: methane, carbon dioxide, $\mathrm{BOD}_{5}, \mathrm{SS}, \mathrm{NH}_{3}-\mathrm{N}$, nutrients (N, $\mathrm{P}$, $\mathrm{K})$, and income. The details of these methods are shown in Appendix A.

\subsection{Benefit assessment}

\subsubsection{Theoretical framework}

Urban ecosan is a kind of social-economic-natural complex ecological system (Ma and Wang, 1984); the structure and the function of the ecosan system are shown in Fig. 2. The ecologicaleconomic assessment includes the following factors:

(1) Natural factor: global warming and regional eco-service. The maximum, minimum, and average values of GHGs, water pollutants, and nutrients reclaimed for food production (see Appendix A) were calculated.

(2) Social factor: human health and employment opportunities. Direct and indirect impacts on human health were studied and the increase of direct employment opportunity was analyzed.

$\left.\begin{array}{c}\text { U1 Centralized sewage plant } \\ \text { U2 Centralized faeces plant } \\ \text { U3 Decentralized digest } \\ \text { U4 Storage }\end{array}\right] \times\left[\begin{array}{c}\text { Grey water } \\ \text { S1 Centralized sewage plant } \\ \text { S2 Decentralized sewage facility }\end{array}\right]$

(3) Economic factor: capital cost, running cost and benefits, benefits includes:

- Recycle of methane, which was assumed to convert to electricity and the cost of the electricity generator was subtracted from the benefit.

- Reduction of methane emission, the benefit was calculated under the current carbon exchanging market through the clean development mechanism (CDM), about $8 \mathrm{USD} / \mathrm{t} \mathrm{CO}_{2} \mathrm{e}$.

- Reclaimed water, the capital cost of facilities, pipes, and the running cost of reclaiming processes were subtracted from the benefit.

- Reclaimed nutrients, the nutrients were converted to total $\mathrm{N}$, $\mathrm{P}_{2} \mathrm{O}_{5}, \mathrm{~K}_{2} \mathrm{O}$ equivalents, and the benefits were based on the current fertilizer price.

\subsubsection{Scenario design}

(1) Traditional centralized treatment (CT): C1 was applied. Solid waste, faeces, and sewage were centralized treated under the end-of-pipe model and the nutrients, energy, and water were not recycled.

(2) Centralized ecosan (CE): C2-C4 were applied. Solid waste, faeces, and sewage were centralized treated under the ecosan model, and the nutrients, energy, and water were recycled as much as possible.

(3) Decentralize and centralize mixed ecosan (ME): C2-C4 and D1-D4 were applied. Centralized ecosan technologies were 


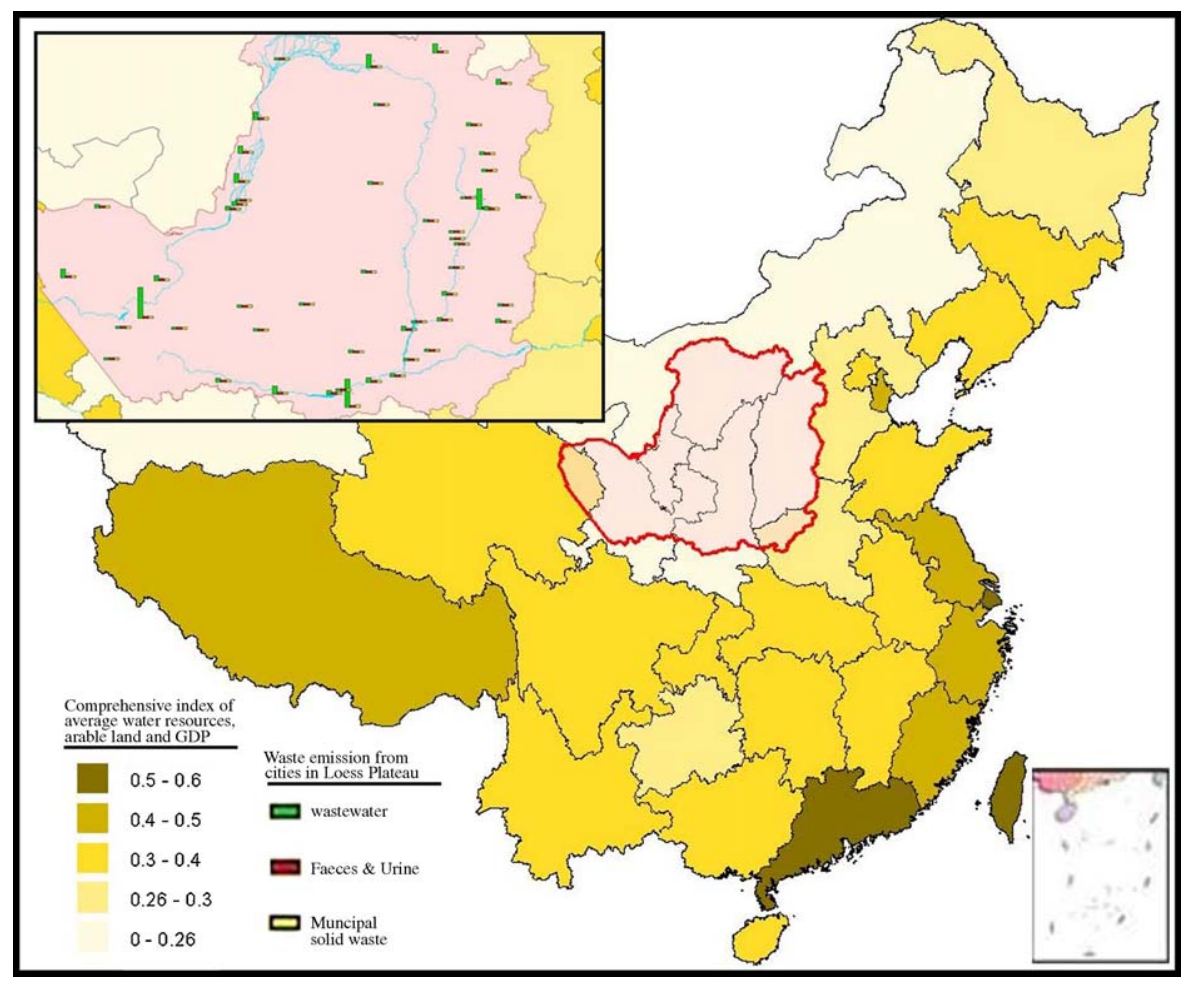

Fig. 1. The study area and distribution of ecosan demand in China.

applied at already built urban areas, while decentralized technologies were applied at newly built urban areas.

\section{Results and analysis}

\subsection{Current sanitary system}

We investigated the urban sanitary systems of typical Loess Plateau cities, such as Taiyuan, Xi'an, Lanzhou, and Yinchuan. We found that the cities had poor sanitation and the existing sanitary systems were centralized and similar among cities (see Fig. 3 ). The characteristics of the current system were as follows:

- Fourteen $\mathrm{Tg}$ of solid waste (organic fraction was about 50\%) was generated, while only $39 \%$ of them was treated harmlessly and $86 \%$ of them was disposed in 44 landfill facilities (National Bureau of Statistics of China, 1999-2006). Landfills in many cities were poorly designed and engineered. The compost was of low quality because of the out-of-date equipment and lack of source separation (Wang and Nie, 2001).

Table 1

Ecosan systems by integrating sanitary technologies.

\begin{tabular}{|c|c|c|}
\hline ID & Integrating sanitary technologies & Classification \\
\hline $\mathrm{C} 1$ & $\begin{array}{l}\text { Solid waste centralized landfill (with no landfill gas recycling facilities) } \\
\text { Faeces and urine are flushed and treated with grey water (with no sludge compressing and reclaiming facilities) }\end{array}$ & Centralized \\
\hline $\mathrm{C} 2$ & $\begin{array}{l}\text { Solid waste centralized landfill (with landfill gas recycling facilities) } \\
\text { Faeces and urine are flushed and treated with grey water (with sludge compressing and reclaiming facilities) }\end{array}$ & Centralized \\
\hline $\mathrm{C} 3$ & $\begin{array}{l}\text { Food waste, faeces, and urine (flush toilet) centralized digest } \\
\text { Grey water centralized treated }\end{array}$ & Centralized \\
\hline C4 & $\begin{array}{l}\text { Food waste centralized compost } \\
\text { Faeces and urine (flush toilet) centralized digest } \\
\text { Grey water centralized treated }\end{array}$ & Centralized \\
\hline D1 & $\begin{array}{l}\text { Food waste and faeces (dry toilet) decentralized compost } \\
\text { Urine decentralized storage and recycle } \\
\text { Grey water decentralized treated }\end{array}$ & Decentralized \\
\hline D2 & $\begin{array}{l}\text { Food waste, faeces, and urine (flush toilet) decentralized digest } \\
\text { Grey water decentralized treated }\end{array}$ & Decentralized \\
\hline D3 & $\begin{array}{l}\text { Food waste and faeces (flush toilet) decentralized digest } \\
\text { Urine decentralized storage and recycle } \\
\text { Grey water decentralized treated }\end{array}$ & Decentralized \\
\hline D4 & $\begin{array}{l}\text { Food waste decentralized compost } \\
\text { Faeces (flush toilet) decentralized digest } \\
\text { Urine decentralized storage and recycle } \\
\text { Grey water decentralized treated }\end{array}$ & Decentralized \\
\hline
\end{tabular}




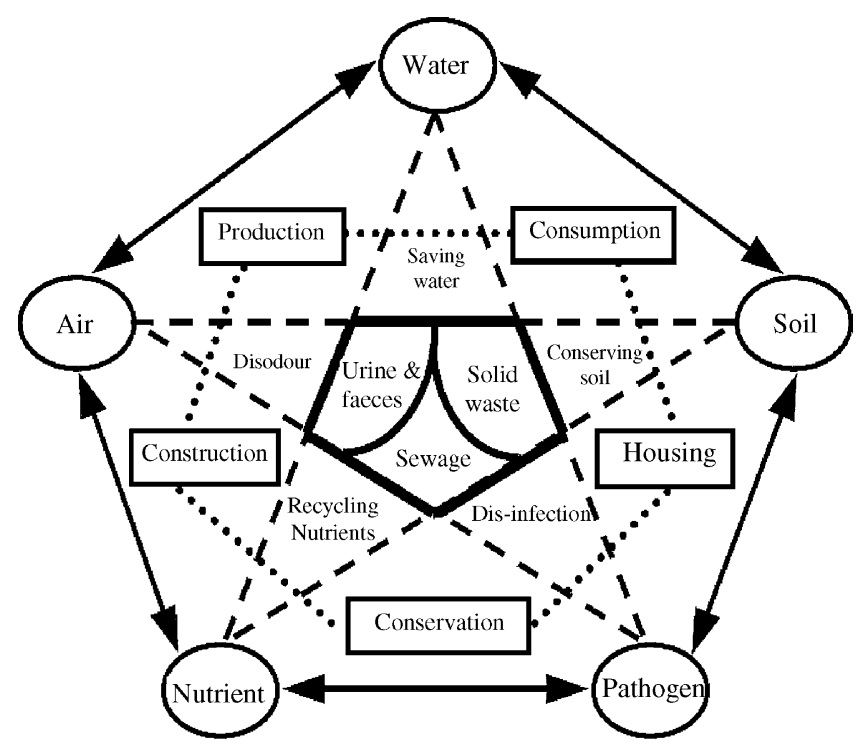

- $\mathbf{n}$ - Social system .......... Economic system

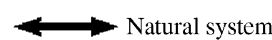

Fig. 2. The structure and functions of an ecosan system.

- Most faeces produced by the residential districts were discharged to the sewer pipe system. Faecal residues discharged from public toilets (about 3.4 million/year) were collected and $37 \%$ of them were treated in faecal treatment plants; otherwise, they were directly reclaimed to the farmland.

- Twenty-nine cities lack sewage treatment plants (about 57\%). Thirty-three percent of wastewater was treated in centralized plants and about $60 \%$ of sludge had low quality.

The natural and social conditions of Loess Plateau made the sanitary problems even serious:
- Lack of water: surface water, ground water, and rainwater were only $37 \%, 62 \%$, and $39 \%$ of the national average, respectively (National Bureau of Statistics of China, 1999-2006).

- Less developed: the average gross domestic product (GDP) was only $63 \%$ of the national average (National Bureau of Statistics of China, 1999-2006).

In this region, the farm land was barren and the organic matter in soils was below 1\% (Institute of Soil Science CAS, 1986), the nutrient demands for farming were huge.

A comprehensive index integrating the factors of average water resource, arable farmland, and average GDP was set to study the distribution of ecosan demand in China (see Fig. 1). We found that the index of the study area is the lowest among all the regions in China.

\subsection{Material, energy, and money flow of ecosan technical systems}

Table 2 shows the material, energy, and money flow of ecosan systems.

\subsection{Natural assessment}

\subsubsection{Global climate impacts}

The emission of GHGs is shown in Fig. 4. If no reduction measures are taken, $9.89 \mathrm{Tg}$ of GHGs will be released (CT, year 2030 ). If $80 \%$ methane produced by the solid waste landfill and $60 \%$ methane produced by the treatment of sludge were recycled, total emission of GHGs could be reduced to $1.13 \mathrm{Tg}$ of carbon dioxide equivalent (CO2e)/year (CE, year 2030). ME releases less GHGs, only $0.82 \mathrm{Tg} /$ year (year 2030), because decentralized ecosan systems consumed less gasoline and electricity. If the decentralized anaerobic digest is applied and methane is maximally recycled, the GHGs emission could reduce to $0.32 \mathrm{Tg}$, which was only $3.2 \%$ of CT (ME, C3 and D3, year 2030). Fig. 5 shows that the methane recycling potential of CE and ME is at the same level, and

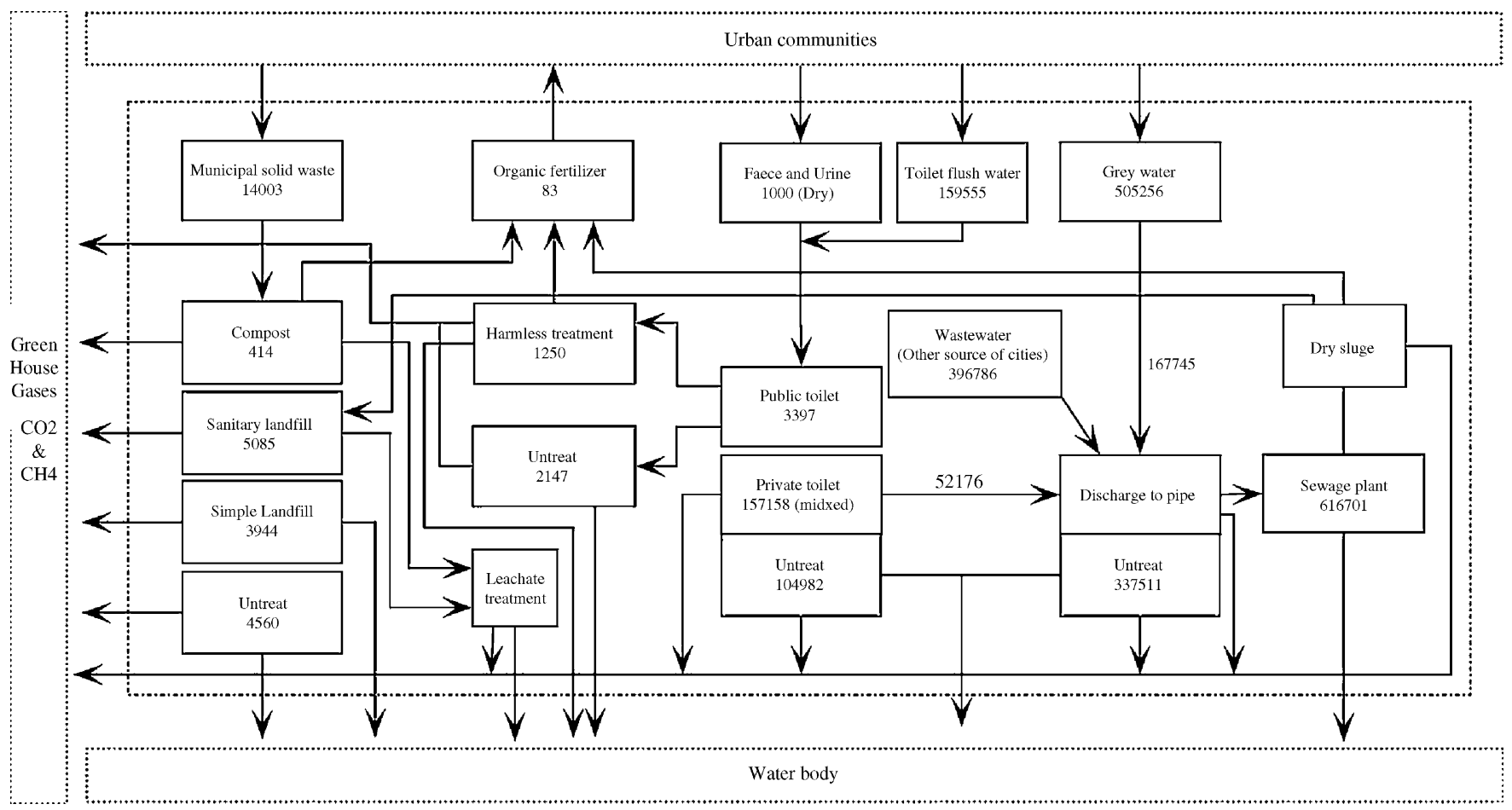

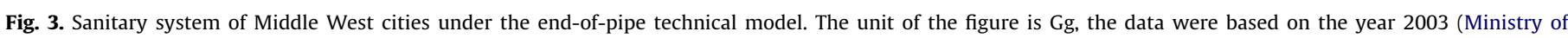
Construction of China, 2004). 
Table 2

Material and money flow of ecosan systems (per $10^{3}$ capita).

\begin{tabular}{|c|c|c|c|c|c|c|c|c|c|c|c|}
\hline \multirow[t]{2}{*}{ Ecosan systems } & \multicolumn{2}{|c|}{ GHGs (Mg/year) } & \multicolumn{3}{|c|}{ Water pollutants (Mg/year) } & \multicolumn{3}{|c|}{$\begin{array}{l}\text { Nutrients reclaiming } \\
\text { potential (Mg/year) }\end{array}$} & \multicolumn{3}{|c|}{$\begin{array}{l}\text { Capital \& Running cost, thousands } \\
\text { (RMB/year) }^{\mathrm{a}}\end{array}$} \\
\hline & $\mathrm{CH}_{4}$ recycle & $\mathrm{CO}_{2} \mathrm{e}$ emission & $\mathrm{BOD}_{5}$ & SS & NH3-N & $\mathrm{N}$ & $\mathrm{P}$ & $\mathrm{K}$ & Capital cost & Running cost & Sum \\
\hline $\mathrm{C} 1$ & 0.00 & 4150.13 & 10.99 & 11.00 & 9.13 & 0.35 & 0.08 & 0.35 & 346.3 & 386.7 & 733.0 \\
\hline $\mathrm{C} 2$ & 148.04 & 1041.21 & 10.99 & 11.00 & 9.13 & 0.35 & 0.08 & 0.35 & 346.3 & 386.7 & 733.0 \\
\hline $\mathrm{C} 3$ & 159.52 & 177.52 & 11.01 & 11.01 & 9.17 & 12.29 & 2.07 & 3.57 & 392.0 & 418.5 & 810.5 \\
\hline C4 & 4.38 & 198.65 & 10.95 & 10.95 & 9.13 & 12.29 & 2.07 & 3.57 & 361.6 & 395.1 & 756.7 \\
\hline D1 & 0.00 & 45.00 & 5.55 & 2.77 & 2.77 & 48.16 & 7.48 & 13.40 & 88.8 & 179.3 & 268.1 \\
\hline $\mathrm{D} 2$ & 164.24 & 32.85 & 7.30 & 3.65 & 3.65 & 13.92 & 2.96 & 5.20 & 141.5 & 240.3 & 381.8 \\
\hline D3 & 162.43 & 26.94 & 5.99 & 2.99 & 2.99 & 47.52 & 7.16 & 12.76 & 184.0 & 267.7 & 451.7 \\
\hline D4 & 7.29 & 47.96 & 7.30 & 3.65 & 3.65 & 7.52 & 2.16 & 3.76 & 173.8 & 303.1 & 476.9 \\
\hline
\end{tabular}

a $1 \mathrm{RMB}=0.133 \mathrm{USD}$

integration of $\mathrm{C} 3$ and $\mathrm{D} 2$ could reuse maximum methane, $0.038 \mathrm{Tg}$ (year 2030).

\subsubsection{Regional eco-service}

(1) Water pollution:

Water pollutants emissions $\left(\mathrm{BOD}_{5}\right)$ of $\mathrm{CT}, \mathrm{CE}$, and $\mathrm{ME}$ are shown in Fig. 6. We found that the $\mathrm{BOD}_{5}$ emission of $\mathrm{CT}$ and $\mathrm{CE}$ is almost the same, and the value of CE fluctuates slightly because the centralized terminal is a two-stage wastewater plant, which has a limitation of effluent quality. ME releases less $\mathrm{BOD}_{5}$ than $\mathrm{CT}$ and $\mathrm{CE}(88 \%)$ since the grey water is separated at the source and the difficulty of wastewater treatment is decreased. D1 applies the technology of UDDT and emits only $0.55 \mathrm{Mg}$ of $\mathrm{BOD}_{5}$ per 1000 people/year, which was the minimum of all ecosan systems.

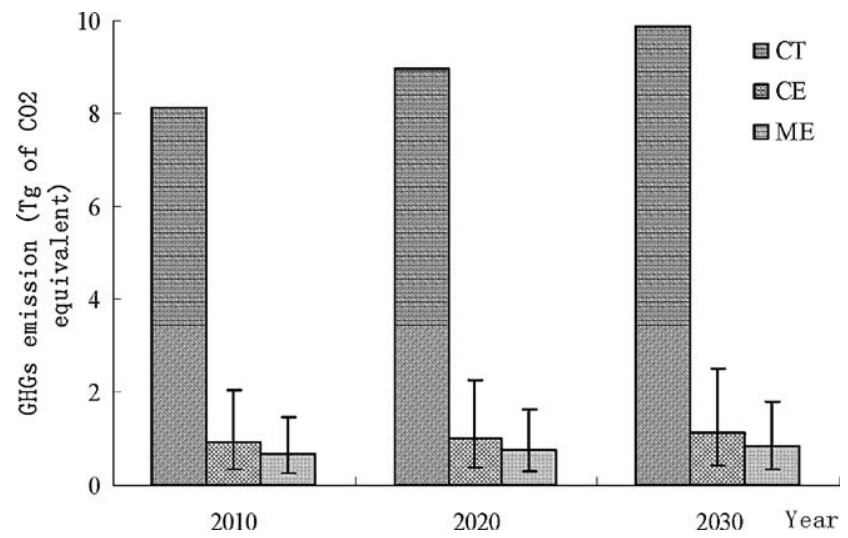

Fig. 4. GHGs emissions of different ecosan developing models.

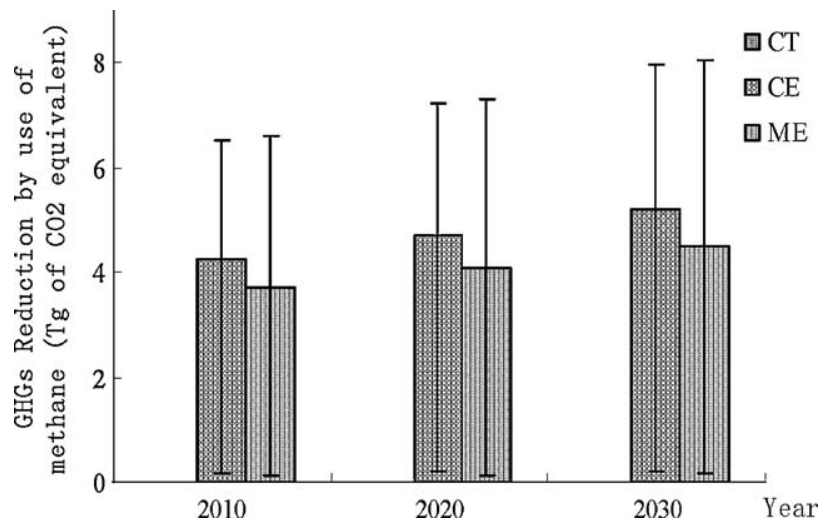

Fig. 5. GHGs reduction of different ecosan developing models.

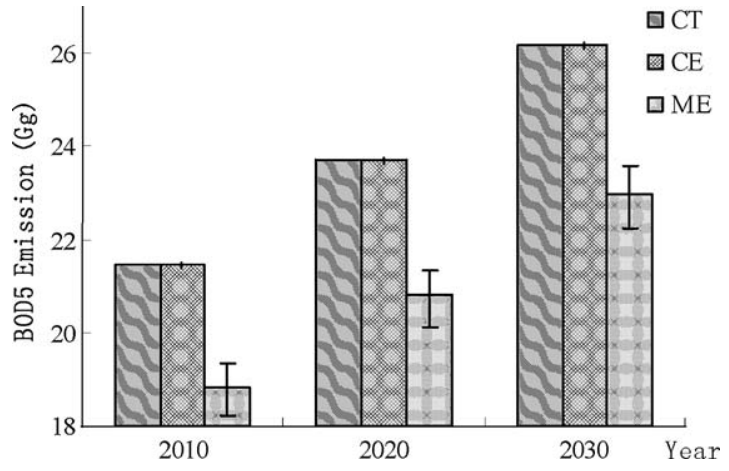

Fig. 6. $\mathrm{BOD}_{5}$ emissions to water bodies of different ecosan developing models.

(2) Nutrients:

Nutrient recycling fluctuates obviously with different ecosan technologies. It seems that decentralized ecosan systems could recycle more nutrients. For example, D1 could recycle maximum nutrients of $4.816,0.748$, and $1.340 \mathrm{Mg}$ of $\mathrm{N}$, $\mathrm{P}$, and $\mathrm{K}$ per 1000 people/year, respectively (see Table 2). Landfill of organic solid waste is the main reason of nutrients loss. For example, $\mathrm{C} 1$ and $\mathrm{C} 2$ could recycle $0.035 \mathrm{Mg}$ of nitrogen per 1000 people/year, which is only $2.8 \%$ of C3.

Increased food production attributed to nutrients reclaim is shown in Fig. 7. On the average, CT, CE, and ME could produce 32.1, 461.4 , and $809.9 \mathrm{Gg}$ of foods, respectively (year 2030). Reclaiming nutrients are important for Loess Plateau area, because the bearing capacity of local farmland has already overloaded three million people in the year 2005 (Chen et al., 1991). Chemical fertilizer was over applied to farmlands to increase food production; the fertilizer application rate may reach $300 \mathrm{~kg} / \mathrm{ha}$ (year 2030), which

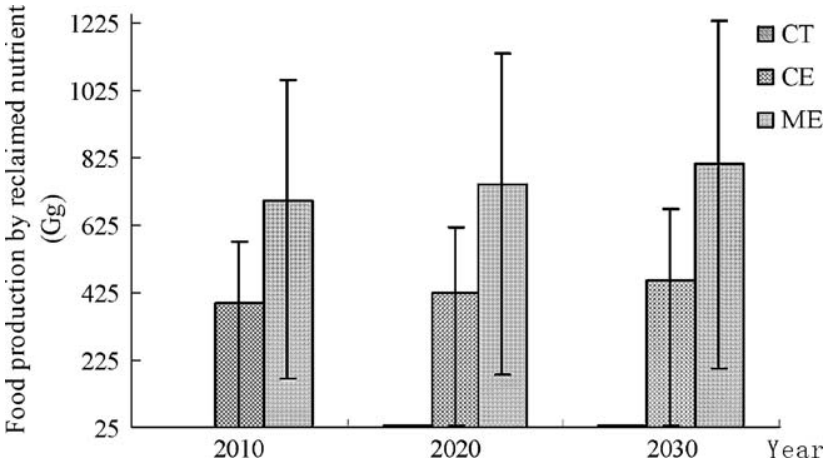

Fig. 7. Food production increase of different ecosan developing models. 


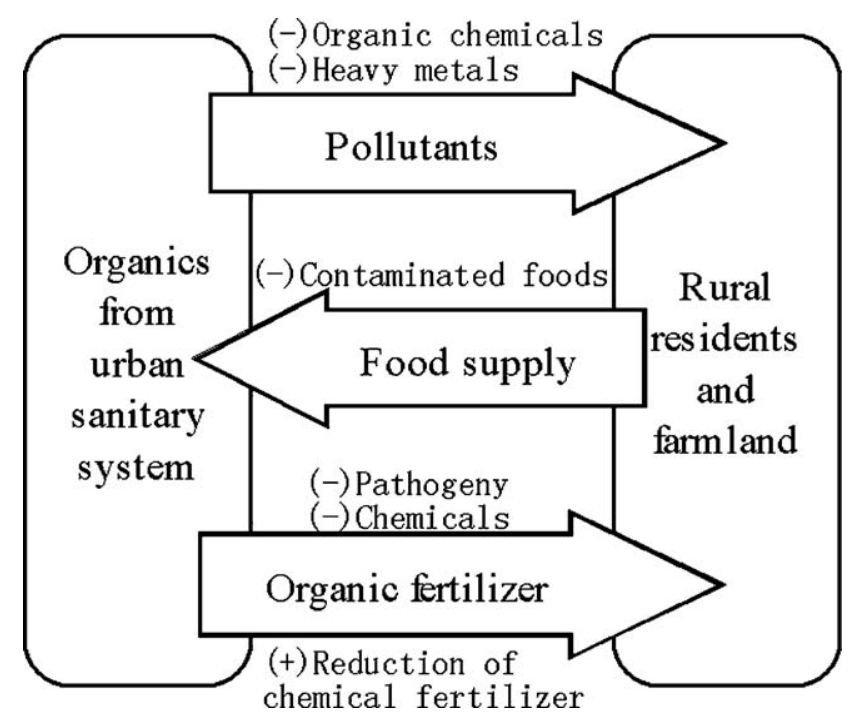

Fig. 8. Mutual health impacts between urban and rural areas.

is higher than $150-225 \mathrm{~kg} / \mathrm{ha}$, the critical application rate of high leaching and runoff risk (Norse, 2003).

Another interesting finding is that the maximum nutrient recycling from urban sanitary system is $16 \%$ of the total nutrient consumption. CE and ME could recycle $0.7-44.2 \mathrm{Gg} /$ year of nitrogen through urban ecosan system, while the fertilizer demand of nitrogen will reach $282 \mathrm{Gg} /$ year. Assuming that $10 \%$ nutrients were assimilated and respirationally exhausted by human beings, then at least $74 \%$ of nitrogen may be lost on the agricultural processes, such as by-products of cereal waste and loss by the flush of rain, hence, the recycling of agricultural waste and conservation of farmland are also important.

\subsection{Social assessment}

\subsubsection{Human health}

Fig. 8 shows the mutual health impact between urban and rural areas. Most rural people do not have centralized freshwater supply, as a result the health risk may be higher. Xu et al. (2003) found that, in the rural areas, the region prevailing with esophageal cancer definitely has excess nitrate in the ground water, which was caused by sewage and chemical fertilizer. We know from the former analysis that (1) water pollutant emission : $\mathrm{CT}>\mathrm{CE}>\mathrm{ME}$; (2) chemical fertilizer reduction through reclaim of nutrients: $\mathrm{ME}>\mathrm{CE}>\mathrm{CT}$. Although the exact quantitative relationships among human health, sewage, and fertilizer were not determined, we could establish the sequence of rural health risks, which were affected by the urban sanitary systems: $C T>C E>M E$. But we should realize that nutrients reclaim need strictly observe the WHO guidelines (WHO, 2006).

\subsubsection{Employment opportunity}

Ecosan could add industries and extend the entire industrial chain of sanitary systems, including the industry of logistics, community management, organic fertilizer production, urban agriculture and forestry, technical consultants and services, and others. The increase of employment opportunity is difficult to evaluate quantificationally, although the direct increase of employment of sanitary systems could be estimated, about 1-2 per thousand people to service the process of segregation, recycling, and maintenance and running the facilities. About $2 \%$ of people in the studied cities are picking up solid waste for a living; they could be trained to service the ecosan systems.

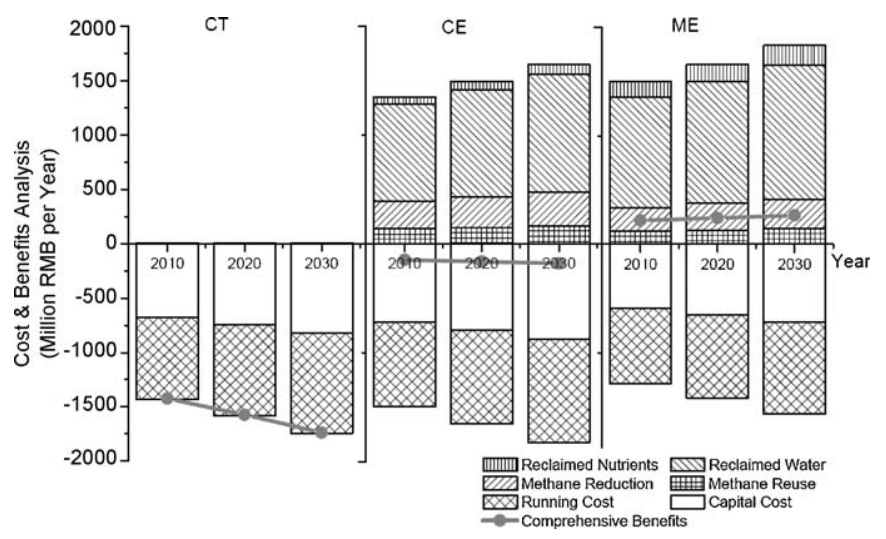

Fig. 9. The comprehensive cost-benefits of different ecosan developing models.

\subsection{Economic assessment}

Cost and benefit analysis of CT, CE, and ME is shown in Fig. 9: (1) $\mathrm{CT}$, the capital, and running cost are increased with the subsequent increase of urban population and the benefit is comparatively less than the cost. Only 5.92-7.17 million RMB benefited by the production of fertilizer, was $0.4 \%$ of the cost; (2) CE, the capital, and running cost were $4.6 \%$ more than $\mathrm{CT}$, except that its potential benefits were higher. When the benefit was taken into account, the net cost was $10 \%$ of $\mathrm{CT}$; and (3) ME, the capital, and running cost were the least, about $89 \%$ and $85 \%$ of CT and CE, as the transport system (vehicles and wastewater pipe networks) of the decentralized ecosan costs less than the centralized. The benefits of ME were 253 and 1.1 times higher than CT and CE, when the benefits were taken into account, net cost of sanitation turned into net benefits, about 267 million RMB/year.

If all wastewater, faeces, and solid waste were harmlessly transferred and treated in the traditional centralized way (CT) in the year 2010, 1.43 billion RMB will be needed for capital and running cost. In the year 2003, there was only an expenditure of 0.31 billion $\mathrm{RMB} / \mathrm{year}$ for the treatment of wastewater and solid waste. If this expenditure increases $10 \%$ year, a gap of 0.83 billion also exists. The unit increase is $0.95 \mathrm{RMB} / \mathrm{Mg}$ of sewage and $8 \mathrm{RMB} /$ year per capita for treatment of solid waste. If we are seeking for technical innovation of ecosan, for instance, the centralized ecosan system (CE) only needs 0.15 billion RMB, while ME could even produce 0.22 billion RMB of net income.

Additionally, clean development mechanism (CDM) was an international cooperation method that was built based on the Kyoto Protocol. It could aid developing countries with the investment of projects that prevent global warming. If ecosan were developed in the studied area, from the year 2010 to 2030 , 0.203-0.248 (CE) and 0.176-0.215 (ME) Tg of methane/year could be recycled. According to the current carbon market ( $8 \$$ $\mathrm{Mg} \mathrm{CO} 2 \mathrm{e}$ ), there were potential benefits of $0.25-0.31$ billion RMB of Chinese Loess Plateau cities through CDM operation. This benefit is 35\% of the capital cost of an ecosan system (sewage, faeces, and solid waste treatment facilities, supporting system for pipes, and transferring vehicles and stations). Therefore, the CDM could be used to ensure the startup investment of ecosan systems.

\section{Conclusion and discussion}

Ecosan systems have the following impacts and benefits: (1) Both centralized and decentralized ecosan systems reduce GHGs and are helpful for preventing global warming. Decentralized ecosan systems reduce more water pollutants 
than centralized systems, while ecosan systems reclaim more nutrients than the traditional system. Thus, ecosan systems have better function of regional eco-service. (2) Ecosan systems have important social impact by reducing the risk of human health and increase employment opportunity. (3) Ecosan systems produce considerable incomes and make the system works sustainable.

Conversely, there are some bottlenecks in developing urban ecosan: (1) lack of policies, legislations, and standards; (2) lack of systems of production, construction, and services; (3) lack of startup investment of research and construction; (4) lack of human resources of management and research and development; (5) lack of education and propaganda. CDM could help developing countries to apply advanced technologies and obtain startup investments, but other compensating mechanisms still need further research. Relative policies and regulations should be developed, such as landfill restriction of unpretreated organic solid waste, charging fees of household wastewater and solid waste, financial subsidies of recycling water and organic waste, and national guidelines on the safe use of reclaimed nutrients. Regional differences and public demands should be respected when developing ecosan projects.

This paper has established a framework for the ecologicaleconomic assessment for understanding and controlling the complexity of ecosan development, further research regarding assessing methodologies still need to be conducted to provide evidences and reasons for determinating compensation policies and financial supports.

\section{Acknowledgements}

Thanks are due to the support of three foundations: National Nature Science Foundation of China (70433001) and the Knowledge Innovation Project of The Chinese Academy of Sciences (KZCX2-YW-422 and KZCX2-YW-324). Thanks are also due to the colleagues of Research Centre of Eco-Environmental Sciences, CAS, and the reviewers who helped me to improve the paper.

\section{Appendix A. Material and money flow of integrated ecosan technical systems}

\section{A.1. GHGs emission and reduction}

The sources of GHGs included : solid waste landfill digest and transfer; faeces and urine digest; sludge digest, etc. The calculations were based on the methodologies of the United Nations Framework of Convention on Climate Change (IPCC, 2000, 2001). The carbon dioxide emission from biomass anaerobic decay and aerobic treatment processes was considered GHGs neutral according to the UNFCCC methodology, the carbon dioxide emission from combustion of fossil fuel and grid electricity, emitted by transportation and auxiliary equipments was included (UNFCCC/CCNUCC, 2006). The parameters were based on the data of local investigations and statistics. If there were no available data to be applied, we used the experiential default values for Asian developing countries recommended by ICPP and UNFCCC, or the data reported by relative references.

\section{A.2. Water pollutants}

Water pollutants included $\mathrm{BOD}_{5}, \mathrm{NH}_{3}-\mathrm{N}$, and SS. The sources of water pollutants emission were : landfill leachate treatment plants, faeces treatment plants, and decentralized and centralized wastewater treatment plants. In China, emitted wastewater from such sources should reach the second-grade level, which was regulated in the integrated wastewater discharge standard (GB 8978-1996). Therefore, we assumed that the quality of emitted wastewater from such sources was: $30 \mathrm{mg} \mathrm{L}^{-1}, 30 \mathrm{mg} \mathrm{L}^{-1}, 25 \mathrm{mg} \mathrm{L}^{-1}$ for $\mathrm{BOD}_{5}, \mathrm{NH}_{3}-\mathrm{N}$, and SS, respectively. Consequently, there were no similar national standard to evaluate the quality of emissions of decentralized grey water treatment facilities. As a result, we studied many cases of constructed wetland and evaluated by an estimate value of case studies (Lens et al., 2001), which were $20 \mathrm{mg} \mathrm{L}^{-1}, 10 \mathrm{mg} \mathrm{L}^{-1}$, $10 \mathrm{mg} \mathrm{L}^{-1}$ for $\mathrm{BOD}_{5}, \mathrm{NH}_{3}-\mathrm{N}$, and SS, respectively.

\section{A.3. Nutrients}

Nutrients included were nitrogen $(\mathrm{N})$, phosphorus $(\mathrm{P})$, and kalium (K). The sources of potential recyclable nutrients included food waste, faeces, urine, and grey water. The characteristics (N, P, K contents) of solid waste, faeces, urine, and grey water were based on former studies (Tchobanoglous et al., 2000; Wang and Nie, 2001; Lens et al., 2001).

\section{A.4. Capital and running cost}

- Capital cost included treatment plants or facilities of solid waste, faeces, urine, and grey water; vehicles and facilities for the transportation of solid waste; pipes, etc. The capital costs of inhabiting buildings and facilities of households were not included. We assumed that annual capital cost was one tenth of the total capital cost.

- Running cost included treatment cost of plants or facilities, cost of vehicles, labors, etc. However, maintenance of household facilities was not included.

- The Chinese Ministry of Construction has issued a series standards of constructing projects' economic evaluation, including landfill, compost, digestion, and wastewater treatment projects (Ministry of Construction of China, 1996, 2001). If there are no available standards, we referred to the similar projects in China.

\section{A.5. Increased food production}

The increased food production, attributed to the reclaimed nutrients of ecosan systems, was calculated based on the farmland productivity of different provinces. The formula was as follows:

$Y_{i, j}=Y 0_{i, j} \cdot \sqrt[3]{\frac{X_{\mathrm{N}}}{X_{\mathrm{N} 0}} \cdot \frac{X_{\mathrm{P}}}{X_{\mathrm{P} 0}} \cdot \frac{X_{\mathrm{K}}}{X_{\mathrm{K} 0}}}$

where

$Y_{i, j}$ is the increased food production attributed to the reclaimed nutrients;

$i$ is the year;

$j$ is the province;

$Y \mathrm{O}_{i, j}$ is the predicted food production (affected by such factors: the soil condition, potential sunlight, accumulated temperature, productive capacity, irrigation capacity, and fertilizer demands);

$X_{\mathrm{N}}, X_{\mathrm{P}}$, and $X_{\mathrm{K}}$ are the reclaimed nitrogen, phosphorus, and kalium, which are converted to the equivalent of $\mathrm{N}, \mathrm{P}_{2} \mathrm{O}_{5}$, and $\mathrm{K}_{2} \mathrm{O}$, respectively;

$X_{\mathrm{NO}}, X_{\mathrm{P} 0}$, and $X_{\mathrm{K} 0}$ are the demanded nitrogen, phosphorus, and kalium for $Y_{\max }$, which are converted to the equivalents of $\mathrm{N}$, $\mathrm{P}_{2} \mathrm{O}_{5}$, and $\mathrm{K}_{2} \mathrm{O}$, respectively. 


\section{References}

Black, M., 2001. Official conference report. In: Winblad, U. (Ed.), First International Conference on Ecological Sanitation, Stockholm, WKAB, pp. 1-7.

Chen, B.M., Xiang, P.N., Feng, Z.M., Chen, G.N., 1991. The Farmland Productive Capacity and the Population Carrying Capacity of China. China Renmin University Press, Beijing, 1551 pp. (in Chinese).

Chen, Z.L., Zhou, C.B., Zhou, L., Huang, L., Zhang, W.J., Xiong, S.L., 2005. Study of underground fecal waste and kitchen garbage treatment system. Water and Wastewater Engineering 31, 74-79 (in Chinese, with English abstract).

Dellstrom Rosenquist, L.E., 2005. A psychosocial analysis of the human-sanitation nexus. Journal of Environmental Psychology 25, 335-346.

Institute of Soil Science CAS, 1986. The Soil Atlas of China. Cartographic Publishing House, Beijing, 31-32 pp.

IPCC, 2000. Good Practice Guidance and Uncertainty Management in National Greenhouse Gas Inventories. 4-88788-000-6.

IPCC, 2001. Climate Change 2001: Working group I. The Scientific Basis. .

Langergraber, G., Muellegger, E., 2005. Ecological sanitation-A way to solve global sanitation problems? Environment International 31, 433-444.

Lens, P., Zeeman, G., Lettinga, G., 2001. Decentralised Sanitaion and Reuse-Concepts, System and Implementation. IWA Publishing, 190-210 pp.

Lundie, S., Peters, G.M., 2005. Life cycle assessment of food waste management options. Journal of Cleaner Production 13, 275-286.

Lusk, P., 1998. Methane Recovery from Animal Manures: The Current Opportunities Casebook. National Renewable Energy Lab Publication nrel/sr-580-25145 (DOE Contract No. De-ac36-83ch10093).

Ma, S.J., Wang, R.S., 1984. The social-economic-natural complex ecological system. Acta Ecologica Sinica 4, 1-9 (in Chinese)

Magid, J., Eilersen, A.M., Wrisberg, S., Henze, M., 2006. Possibilities and barriers for recirculation of nutrients and organic matter from urban to rural areas: a technical theoretical framework applied to the medium-sized town Hillerod, Denmark. Ecological Engineering 28, 44-54.

Mata-Alvarez, J., Mace, S., Llabres, P., 2000. Anaerobic digestion of organic solid wastes. An overview of research achievements and perspectives. Bioresource Technology 74, 3-16.

Ministry of Construction of China, 1996. Constructing Standards and Technological Criterion of Municipal Solid Waste Landfill Projects. China Planning Press, Beijing, $47 \mathrm{pp}$.

Ministry of Construction of China, 2001. Constructing Standards and Technological Criterion of Municipal Wastewater Treatment Projects. China Planning Press, Beijing, 70 pp.

Ministry of Construction of China, 2004. Urban Construction Statistic Yearbook (2003). China Construction Industry Publishers, Beijing, 861 pp.

National Bureau of Statistics of China, 2007. China Statistical Yearbook (2006). China Statistics Press, Beijing, 1031 pp.
Nawab, B., Nyborg, I.L.P., Esser, K.B., Jenssen, P.D., 2006. Cultural preferences in designing ecological sanitation systems in North West Frontier Province, Pakistan. Journal of Environmental Psychology 26, 236-246.

Norse, D, 2003. Fertilizers and world food demand implications for environmental stresses. In: International Fertilizer Industry Association, IFA-FAO Agriculture Conference: Global Food Security and the Role of Sustainable Fertilization.

Office of National Coordination Committee on Climate Change, 2001. The People's Republic of China Initial National Communication on Climate Change. http:// www.ccchina.gov.cn/en/NewsInfo.asp?NewsId=7111 (2007-02-09; 2008-0102).

Otterpohl, R., Grottker, M., Lange, J., 1997. Sustainable water and waste management in urban areas. Water Science and Technology 35, 121-133.

Saravanan, V.S., 2008. A systems approach to unravel complex water management institutions. Ecological Complexity 5, 202-215.

Shmelev, S.E., Powell, J.R., 2006. Ecological-economic modelling for strategic regional waste management systems. Ecological Economics 59, 115-130.

Sonesson, U., Bjorklund, A., Carlsson, M., Dalemo, M., 2000. Environmental and economic analysis of management systems for biodegradable waste. Resources, Conservation and Recycling 28, 29-53.

Sun, L.X., Li, R., Rosemarin, A., Xiao, J., Winblad, U., 2006. China-Sweden Erdos Ecotown Project, Dong Sheng, Inner Mongolia, China. http://www.ecosanres.org/ pdf_files/Fact_sheets/Fact_Sheet_11ls.pdf (2006-8; 2007-5-14).

Tainter, J.A., 2006. Social complexity and sustainability. Ecological Complexity 3, 91-103.

Tchobanoglous, G., Theisen, H., Vigil, S., 2000. Integrated Solid Waste Management Engineering Principles and Management Issues. McGraw-Hill, New York, 978 pp.

UNFCCC/CCNUCC, 2006. Am0039. Methane Emissions Reduction from Organic Waste Water and Bioorganic Solid Waste Using Cocomposting. .

Wang, H., Nie, Y., 2001. Municipal solid waste characteristics and management in china. Air \& Waste Management Association 51, 250-263.

Wang, R.S., 2001. System consideration of eco-sanitation in china. In: Winblad, U. (Ed.), First International Conference on Ecological Sanitation.

Wang, R.S., Zhou, C.B., 2007. Potentials, challenges and strategies for china's ecosanitation development. In: Third International Conference on Ecological Sanitation.

WHO, 2006. Volume 1: Policy and Regulatory Aspects, Who Guidelines for the Safe Use of Wastewater, Excreta and Greywater.

Wilderer, P.A., Schreff, D., 2000. Decentralized and centralized wastewater management: A challenge for technology developers. Water Science and Technology 41, $1-8$.

Winblad, U., Hebert, M.S., 2006. Ecological Sanitation-Principles, Measures and Applications. China Architecture and Building Press, Beijing, 140 pp. (in Chinese).

Xu, Z.X., Tan, J.J., Chen, F.L., Si, J.H., Xu, B.N., 2003. Fertilizer, Wastewater and Esophageal Cancer. Science Publisher, Beijing, 266 pp. (in Chinese). 